\title{
Nitric oxide production by the alveolar compartment of the lungs in cirrhotic patients
}

\author{
B. Degano*, M. Mittaine ${ }^{\#}$, P. Hervé*, ${ }^{*}$, J. Rami" ${ }^{\#}$ N. Kamar+, B. Suc ${ }^{+}$, \\ D. Rivière ${ }^{\#}$ and L. Rostaing
}

ABSTRACT: In cirrhotic patients, alveolar nitric oxide (NO) concentration is increased. This may be secondary to increased output of NO produced by the alveoli (V'A,NO) and/or to decreased lung transfer factor of NO. In advanced liver cirrhosis, NO produced by the alveoli may play a role in abnormalities of pulmonary haemodynamics and gas exchanges. In cirrhotic patients, we aimed to measure $V^{\prime} \mathrm{A}, \mathrm{NO}$ and to compare $V^{\prime} \mathrm{A}, \mathrm{NO}$ with pulmonary haemodynamics and gas exchange parameters.

Measurements were performed in 22 healthy controls and in 29 cirrhotic patients, of whom eight had hepatopulmonary syndrome. Exhaled NO concentrations were measured at multiple expiratory flow rates to derive alveolar NO concentration. V'A,NO was the product of alveolar NO concentration by single breath lung transfer factor for NO.

$V^{\prime}$ A,NO was increased in patients (median (range) 260 (177-341) $\mathrm{nL} \cdot \mathrm{min}^{-1}$ ) compared with controls (79 (60-90), $p<0.0001)$. Alveolar-arterial oxygen tension difference failed to correlate with V'A,NO. However, cardiac index correlated positively and systemic vascular resistance correlated negatively with $V^{\prime} A, N O(r=0.56, p=0.001$ and $r=-0.52, p=0.004$, respectively).

In cirrhotic patients, NO was produced in excess by the alveolar compartment of the lungs. Alveolar NO production was associated with hyperdynamic circulatory syndrome but not with arterial oxygenation impairment.

\section{KEYWORDS: Exhaled nitric oxide, hepatopulmonary syndrome, liver-lung interactions}

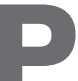
atients with advanced liver disease typically present with progressive systemic, splanchnic and pulmonary vasodilatation. This may lead to a hyperdynamic circulatory syndrome, which associates high cardiac index (CI) and fluid expansion in response to excessive vasodilatation [1, 2]. Impaired arterial oxygenation, ranging from increased alveolar-arterial oxygen tension difference $\left(P \mathrm{~A}-\mathrm{a}, \mathrm{O}_{2}\right)$ to severe hypoxaemia, is also commonly present in patients with liver cirrhosis. In the absence of overt mechanical dysfunction of the lung, these oxygenation abnormalities may be a consequence of ventilation/perfusion mismatch and/or intrapulmonary shunting and/or diffusion impairment of oxygen [3]. In addition, some patients develop hepatopulmonary syndrome (HPS), which consists of abnormal dilatation of pulmonary pre-capillary and capillary vessels either with or without pulmonary arteriovenous communications, whereas alveolar ventilation is preserved [4-6].

Nitric oxide (NO), a biologically active gas, is the main molecule responsible for the vasodilatation and multiple organ malfunctions that characterise hyperdynamic circulatory syndrome [7]. A loss of NO bioavailability in the endothelial cells of the hepatic microcirculation contrasts with an increase in NO production by the endothelial cells in the arteries of the systemic and pulmonary circulatory systems. In animal models of HPS, pulmonary vascular dilatation, gas exchange abnormalities and blunted pulmonary vasopressor response are all linked to increased expression and activity of pulmonary NO synthases [5, 8-10]. However, in humans, the role of $\mathrm{NO}$ in arterial oxygenation impairment is still under debate [11].

NO can be easily and noninvasively measured in exhaled air and is thought to reflect a balance between production and catabolism within the respiratory tract [12]. Measurement of exhaled NO at multiple controlled expiratory flow rates allows partition into airway and alveolar NO components $[13,14]$, and the additional measurement of NO lung transfer enables the calculation of output of NO produced by the alveoli $\left(V^{\prime} \mathrm{A}, \mathrm{NO}\right)$ [15].

\section{AFFILIATIONS}

* Service de Pneumologie et Réanimation Respiratoire, Centre National de Référence de l'Hypertension Artérielle Pulmonaire, Hôpital Antoine Béclère, Clamart,

\# Service d'Exploration Fonctionnelle Respiratoire, CHU Larrey, +Dept de Néphrologie, Dialyse et Transplantation d'Organes, $\mathrm{CHU}$ Rangueil, Toulouse, and

- Centre Chirurgical MarieLannelongue, Le Plessis-Robinson, France.

\section{CORRESPONDENCE}

B. Degano

Service de Pneumologie

Hôpital Antoine Béclère

157 rue de la Porte de Trivaux

92141 Clamart

France

E-mail: degano.b@gmail.com

Received:

Sept 282008

Accepted after revision:

Dec 142008

First published online:

Jan 072009 
In cirrhosis, alveolar $\mathrm{NO}$ concentration $(\mathrm{CA}, \mathrm{NO})$ is increased compared with normal subjects [16], but measurement of $V^{\prime}$ A,NO has not previously been reported.

In cirrhotic patients awaiting liver transplantation at our institution, we aimed to: 1) measure $V^{\prime} \mathrm{A}, \mathrm{NO}$, and 2) assess the relationships between $V^{\prime} \mathrm{A}, \mathrm{NO}$, oxygenation parameters and pulmonary haemodynamics.

\section{MATERIALS AND METHODS Study subjects}

From November 2006 to October 2007, 29 patients awaiting liver transplantation at Toulouse University Hospital (Toulouse, France) were investigated. All the patients had biopsy-proven liver cirrhosis. Physical examination findings and blood data were analysed to determine the severity of liver disease according to the criteria of CHILD and TURCOTTE [17]. None of the patients had primary lung disease. Patients were not included if they had primary cardiac disease (including systolic and diastolic left heart disease, and mitral and/or aortic stenosis and/or regurgitation) or portopulmonary hypertension. Subjects with allergy and/or asthma were also excluded. The study was approved by our institutional review board (Toulouse University Hospital) and informed consent was obtained from each patient.

\section{Pulmonary function tests}

Measurement of lung volumes and single-breath transfer factor of the lung for carbon monoxide $(T \mathrm{~L}, \mathrm{CO})$ was performed according to the European Respiratory Society (ERS) guidelines $[18,19]$.

Arterial blood gases were analysed in patients' breathing room air in a sitting position. $\mathrm{PA}-\mathrm{a}, \mathrm{O}_{2}$ was calculated as follows.

$$
P A-a, O_{2}=P A, O_{2}-P a, O_{2}=F I, O_{2}\left(P a t m-P \mathrm{H}_{2} \mathrm{O}\right)-P a, C_{2} / R E R-P a, O_{2}
$$

Where $\mathrm{PA}, \mathrm{O}_{2}$ is alveolar oxygen tension, $\mathrm{Pa}, \mathrm{O}_{2}$ is arterial oxygen tension, $\mathrm{F} \mathrm{I}_{1} \mathrm{O}_{2}$ inspiratory oxygen fraction, $P$ atm atmospheric pressure, $\mathrm{PH}_{2} \mathrm{O}$ water vapour partial pressure $(47 \mathrm{mmHg})$, $P a, \mathrm{CO}_{2}$ is arterial carbon dioxide tension and RER is respiratory exchange ratio (assumed to be 0.8). The diagnosis of HPS was based on the ERS recommendations [3].

\section{Measurement of NO concentrations in exhaled air}

Measurements were performed in the 29 patients and in 22 healthy controls. Control subjects were matched with patients for age and smoking habits. Current smokers were asked not to smoke for $24 \mathrm{~h}$ prior to NO measurement. Among subjects who were not current smokers, those who responded "no" to the question "Have you ever smoked for as long as a year?" were classified as nonsmokers, and those who responded "yes" were classified as ex-smokers [20]. Patients and controls were asked to abstain from coffee and vegetables during the $24 \mathrm{~h}$ prior to NO measurement.

Measurement of exhaled NO fraction ( $F$ eNO) was performed as recommended by American Thoracic Society/ERS guidelines [21]. Subjects exhaled against a positive pressure of $20 \mathrm{cmH}_{2} \mathrm{O}$ and generated expiratory flows of 50, 100 and $200 \mathrm{~mL} \cdot \mathrm{s}^{-1}$. NO was detected with a chemiluminescent analyser (EndoNO $800{ }_{\circledR}$; SERES, Aix-en-Provence, France) with a lower limit of detection of $1 \mathrm{ppb}$ and an $\mathrm{NO}$ sampling rate of $30 \mathrm{~L} \cdot \mathrm{h}^{-1}$.
Simultaneous measurements of FeNO and expiratory flow were used to calculate NO output. Three consecutive measurements of FeNO were performed for each expiratory flow and the calculated NO output values were represented as a function of the flow rates. Least-square linear regression over the NO output versus the flow-rate data was performed and the linearity of the relationship was verified, i.e. $\mathrm{r}^{2}>0.90$. CA,NO $(\mathrm{ppb})$ and maximal bronchial output of $\mathrm{NO}\left(J^{\prime} \mathrm{aw}, \mathrm{NO} ; \mathrm{nL} \cdot \mathrm{min}^{-1}\right)$ were estimated according to the model recently described by CONDORELLi et al. [13], as follows.

$$
\mathrm{CA}, \mathrm{NO}=\mathrm{S}-\mathrm{I}\left(\left(0.001 \mathrm{~s} \cdot \mathrm{mL}^{-1}\right) /(0.53)\right)
$$

and

$$
J^{\prime} \mathrm{aw}, \mathrm{NO}=(\mathrm{I} / 0.53) \times 0.06
$$

Where $S$ is the slope and $I$ is the $y$-intercept of the linear regression over the $\mathrm{NO}$ output versus the flow rate.

Unlike the model of TSOUKIAS and GEORGE [14], the current model takes into account axial diffusion of NO from the airways that can "contaminate" the alveolar region, and so it is more relevant when estimating CA,NO [13].

\section{Measurement of NO transfer}

Transfer factor of the lung for nitric oxide $(T L, N O)$ was measured during a single breath manoeuvre using automated apparatus (Medisoft, Dinant, Belgium). Subjects were in the sitting position and wore a nose clip. They inhaled a mixture containing $14 \% \mathrm{He}, 21 \% \mathrm{O}_{2}$ balanced with $\mathrm{N}_{2}$ mixed with an $\mathrm{NO} / \mathrm{N}_{2}$ mixture (450 ppm $\mathrm{NO} / \mathrm{N}_{2}$; Air Liquide Santé, Paris, France). The final concentration of $\mathrm{NO}$ in the mixture was $40 \mathrm{ppm}$ and that of $\mathrm{O}_{2}$ was $19.1 \%$. A breath-hold of $4 \mathrm{~s}$ was requested, followed by a rapid expiration. The first $0.9 \mathrm{~L}$ of expired gas was rejected and the following $0.9 \mathrm{~L}$ was sampled and analysed for NO concentration [22].

According to PerILlO et al. [15], $V^{\prime} \mathrm{A}, \mathrm{NO}\left(\mathrm{nL} \cdot \mathrm{min}^{-1}\right)$ was calculated as the product of $\mathrm{TL}, \mathrm{NO}\left(\mathrm{mL} \cdot \mathrm{min}^{-1} \cdot \mathrm{mmHg}^{-1}\right)$ and $\mathrm{CA}, \mathrm{NO}(\mathrm{ppb})$ as follows.

$$
V^{\prime} \mathrm{A}, \mathrm{NO}=T \mathrm{~L}, \mathrm{NO} \times \mathrm{CA}, \mathrm{NO} \times\left(P \mathrm{~atm}-\mathrm{PH}_{2} \mathrm{O}\right) \times 10^{-3}
$$

Where $P$ atm is atmospheric pressure and $\mathrm{PH}_{2} \mathrm{O}$ water vapour partial pressure $(47 \mathrm{mmHg})$.

\section{Right heart catheterisation}

Right heart catheterisation was performed using a 7F, twolumen, thermodilution pressure-measuring tipped catheter (Corodyn TD; Braun Medical, Bethlehem, PA, USA). Cardiac output was measured by the thermodilution technique.

\section{Analysis}

Data were expressed as median (1st-3rd quartile). Comparisons between more than two groups or subgroups were performed with the Kruskal-Wallis test. Comparisons between two groups or subgroups were performed with the Mann-Whitney U-test. Correlations were made by Spearman's test. A p-value $<0.05$ was considered as significant. Analysis was performed using Statview, version 5.0 (SAS Institute, Cary, NC, USA). 


\section{RESULTS}

\section{Demographic characteristics}

Demographic and clinical characteristics of patients and controls are shown in table 1. The majority of patients were male and had cirrhosis caused by alcohol abuse. No significant difference was observed in age, smoking habits or spirometric values between patients and controls. Cirrhotic patients with HPS had lower TL,CO than non-HPS and than healthy controls. $P A-a, \mathrm{O}_{2}$ was significantly higher in HPS patients than in nonHPS patients. Cirrhotic patients had normal mean pulmonary artery pressure, high CI and low pulmonary vascular resistance.

\section{NO measurements}

Table 2 summarises NO measurements in patients and controls. Median $\mathrm{CA}, \mathrm{NO}, V^{\prime} \mathrm{A}, \mathrm{NO}$ and $J^{\prime}$ aw,NO were significantly increased in cirrhotic patients compared with healthy controls. In cirrhotic patients, $\mathrm{CA}, \mathrm{NO}, V^{\prime} \mathrm{A}, \mathrm{NO}$ and $J^{\prime}$ aw,NO did not differ between patients without HPS (3.5 (2.9-6.5) ppb, 260 (178-338) $\mathrm{nL} \cdot \mathrm{min}^{-1}$ and $74(56-116) \mathrm{nL} \cdot \mathrm{min}^{-1}$, respectively) and patients with HPS (3.7 (2.5-7.0) ppb, 260 (175-359) $\mathrm{nL} \cdot \mathrm{min}^{-1}$ and 74 (58130) $\mathrm{nL} \cdot \mathrm{min}^{-1}$, respectively). Patients and controls were either active smokers or nonsmokers. In healthy smoking controls, $J^{\prime}$ aw,NO was significantly lower than in nonsmokers but $\mathrm{CA}, \mathrm{NO}$ and $V^{\prime} \mathrm{A}, \mathrm{NO}$ were similar. In cirrhotic patients, smoking habits had no effect on CA,NO, $V^{\prime} \mathrm{A}, \mathrm{NO}$ and $J^{\prime}$ aw,NO.

\section{Relationship between NO measurements and gas exchange parameters}

We failed to find any correlation between $\mathrm{PA}-\mathrm{a}, \mathrm{O}_{2}$ and $\mathrm{CA}, \mathrm{NO}$ or between $\mathrm{PA}-\mathrm{a}, \mathrm{O}_{2}$ and $V^{\prime} \mathrm{A}, \mathrm{NO}$ (fig. 1). There was significant correlation between $\mathrm{TL}, \mathrm{CO}$ and $\mathrm{CA}, \mathrm{NO}$. However, there was no correlation between $T \mathrm{~L}, \mathrm{CO}$ and $V^{\prime} \mathrm{A}, \mathrm{NO}$ (fig. 1). J'aw,NO was not correlated either with $\mathrm{PA}-\mathrm{a}, \mathrm{O}_{2}$ or with $\mathrm{TL}, \mathrm{CO}$ (data not shown).

\section{Relationship between NO measurements and haemodynamics}

$\mathrm{CI}$ correlated positively with $\mathrm{CA}, \mathrm{NO}(\mathrm{r}=0.41, \mathrm{p}=0.03)$ and $V^{\prime} \mathrm{A}, \mathrm{NO}(\mathrm{r}=0.56, \mathrm{p}=0.001)$ (fig. 2). Systemic vascular resistance (SVR) correlated negatively with $\mathrm{CA}, \mathrm{NO}(\mathrm{r}=-0.39, \mathrm{p}=0.04)$ and with $V^{\prime} \mathrm{A}, \mathrm{NO} \quad(\mathrm{r}=-0.52, \mathrm{p}=0.004) \quad$ (fig. 2). J'aw,NO was not correlated either with CI or with SVR (data not shown).

\section{DISCUSSION}

Our main findings are that in cirrhotic patients: 1) $V^{\prime}$ A,NO was increased compared with healthy volunteers; and 2) $V^{\prime} \mathrm{A}, \mathrm{NO}$ failed to correlate with $\mathrm{PA}-\mathrm{a}, \mathrm{O}_{2}$ but correlated positively with CI.

An increase in FENO in cirrhotic patients was first reported $>10$ yrs ago. CREMONA et al. [23] and Rolla et al. [24] showed that NO concentrations measured in exhaled air from patients with advanced liver cirrhosis were increased compared with controls. It must be stressed that the technique used to collect exhaled air in these studies was markedly different from the current recommendations [21]. Exhalations were performed without closure of the soft palate and patients wore a nose clip, two conditions which are now known to considerably increase the nasal contribution of NO measured in exhaled air [21]. Moreover, expiratory flow rates were not recorded, and it has been clearly demonstrated that NO concentration in exhaled air is inversely dependent on expiratory flow rate [14]. By measuring exhaled $\mathrm{NO}$ at multiple controlled expiratory flow rates and applying the two-compartment model of TsOUKIAS

TABLE 1 Demographic, functional and haemodynamic characteristics of cirrhotic patients and healthy volunteers

Cirrhotic patients

Non-HPS HPS

\section{Subjects $n$}

Age yrs

Sex $M / F$

Tobacco smoking yes/no $n$

Alcohol/viral hepatitis/others $\mathbf{n}$

Child grade $A / B / C$ n

TLC \% pred

FEV $1 /$ VC \%

$T L, C O \%$ pred

$\mathrm{Pa}, \mathrm{O}_{2} \mathrm{mmHg}$

$\mathrm{Pa}, \mathrm{CO}_{2} \mathrm{mmHg}$

$\mathrm{PA}-\mathrm{a}, \mathrm{O}_{2} \mathrm{mmHg}$

$\bar{P}$ pa $\mathrm{mmHg}$

Cardiac index $\mathrm{L} \cdot \mathrm{min}^{-1} \cdot \mathrm{m}^{-2}$

PVR dyn $\cdot \mathbf{s} \cdot \mathbf{c m}^{-5}$

SVR dyn $\cdot \mathbf{s} \cdot \mathbf{c m}^{-5}$

21
$52.9(40.9-58.4)$
$13 / 8$
$9 / 12$
$7 / 6 / 8$
$3 / 3 / 15$
$99(90-110)$
$82(79-86)$
$88(76-92)$
$96(87-107)$
$33(31-36)$
$9(6-19)$
$14(12-16)$
$4.2(3.2-4.8)$
$56(30-89)$
$988(737-1186)$

8

$56.1(48.8-60.6)$

$7 / 1$

$5 / 3$

$7 / 1 / 0$

$0 / 3 / 5$

93 (90-96)

$80(74-87)$

$66(52-75)^{*, \#}$

$64(58-79)^{\#}$

$33(31-37)$

$40(29-48)^{\#}$

$15(12-19)$

$3.9(3.4-4.7)$

$57(44-96)$

720 (594-1060)

Controls

22

48.3 (36.9-55.4)

$16 / 6$

$10 / 12$

99 (94-110)

80 (77-85)

96 (85-101)

Data are presented as mean (1st-3rd quartile), unless otherwise stated. HPS: hepatopulmonary syndrome; M: male; F: female; TLC: total lung capacity; \% pred: \% predicted; FEV1: forced expiratory volume in $1 \mathrm{~s}$; $\mathrm{VC}$ : vital capacity; $T \mathrm{~L}, \mathrm{CO}$ : transfer factor of the lung for carbon monoxide; $P$ a,CO${ }_{2}$ : arterial carbon dioxide tension; $\mathrm{Pa}_{1} \mathrm{O}_{2}$ : arterial oxygen tension; $\mathrm{PA}-\mathrm{a}, \mathrm{O}_{2}$ : alveolar-arterial oxygen tension difference; $\bar{P}$ pa: mean pulmonary artery pressure; PVR: pulmonary vascular resistance; SVR: systemic vascular resistance. ${ }^{*}: p<0.05$ compared with controls; ${ }^{*}: p<0.05$ compared with non-HPS cirrhotic patients. 
TABLE 2 Nitric oxide (NO) measurements in control subjects and patients with liver cirrhosis

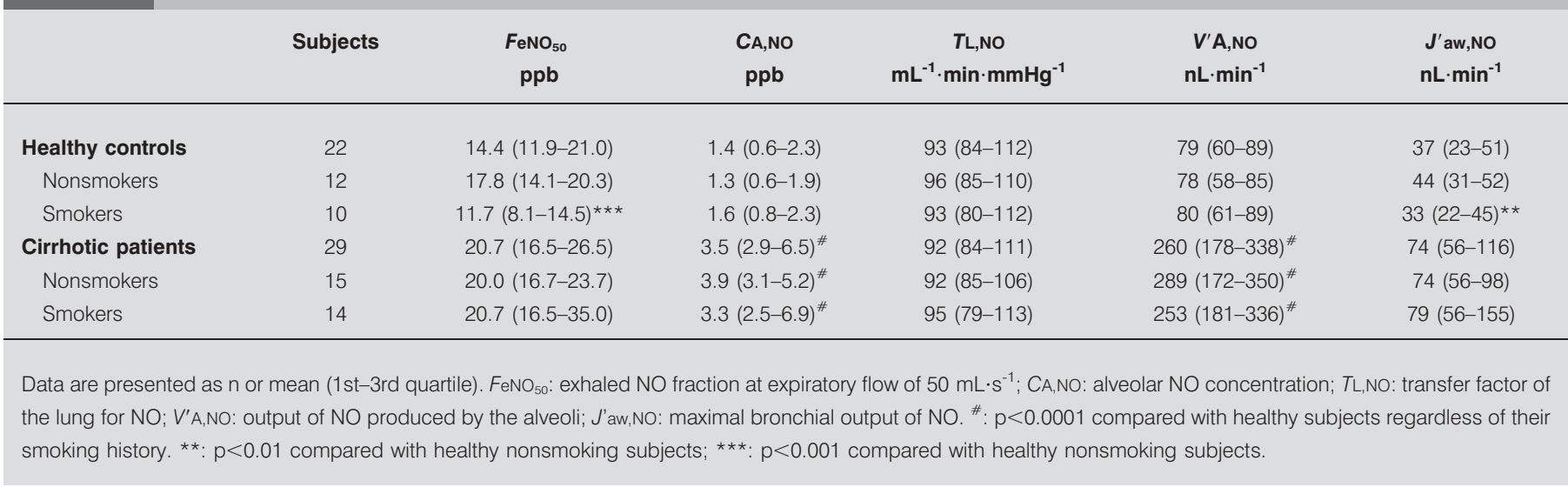

and George [14], Delclaux et al. [16] showed that CA,NO was increased in cirrhotic patients. However, this two-compartment model neglected the axial diffusion of $\mathrm{NO}$ from the airway tree, which can contaminate the alveolar region and so lead to a falsely elevated estimate of CA,NO. Therefore, we used the model recently described by CONDORELLI et al. [13], which takes axial diffusion of $\mathrm{NO}$ into account when estimating CA,NO. This model was initially tested in a limited number of healthy subjects and $\mathrm{CA}, \mathrm{NO}$ was found to be near zero [13]. By contrast, in our series of cirrhotic patients we found that $\mathrm{CA}, \mathrm{NO}$

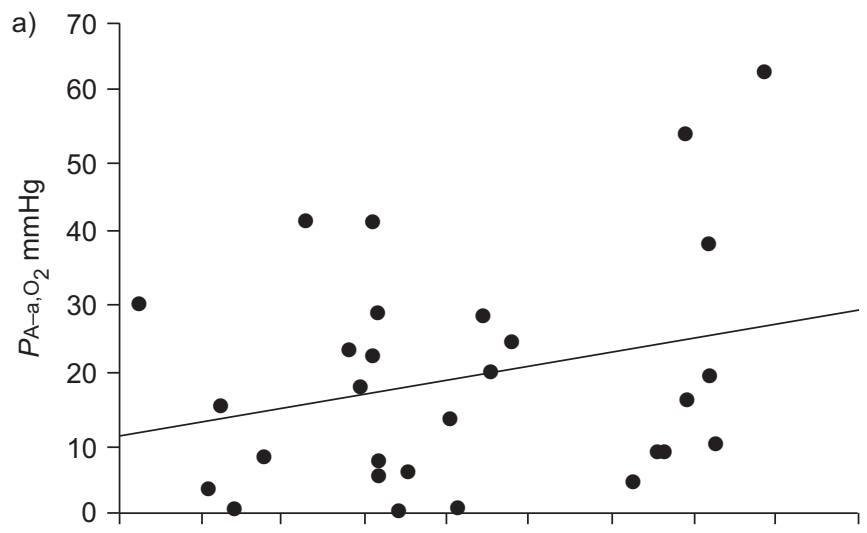

b)
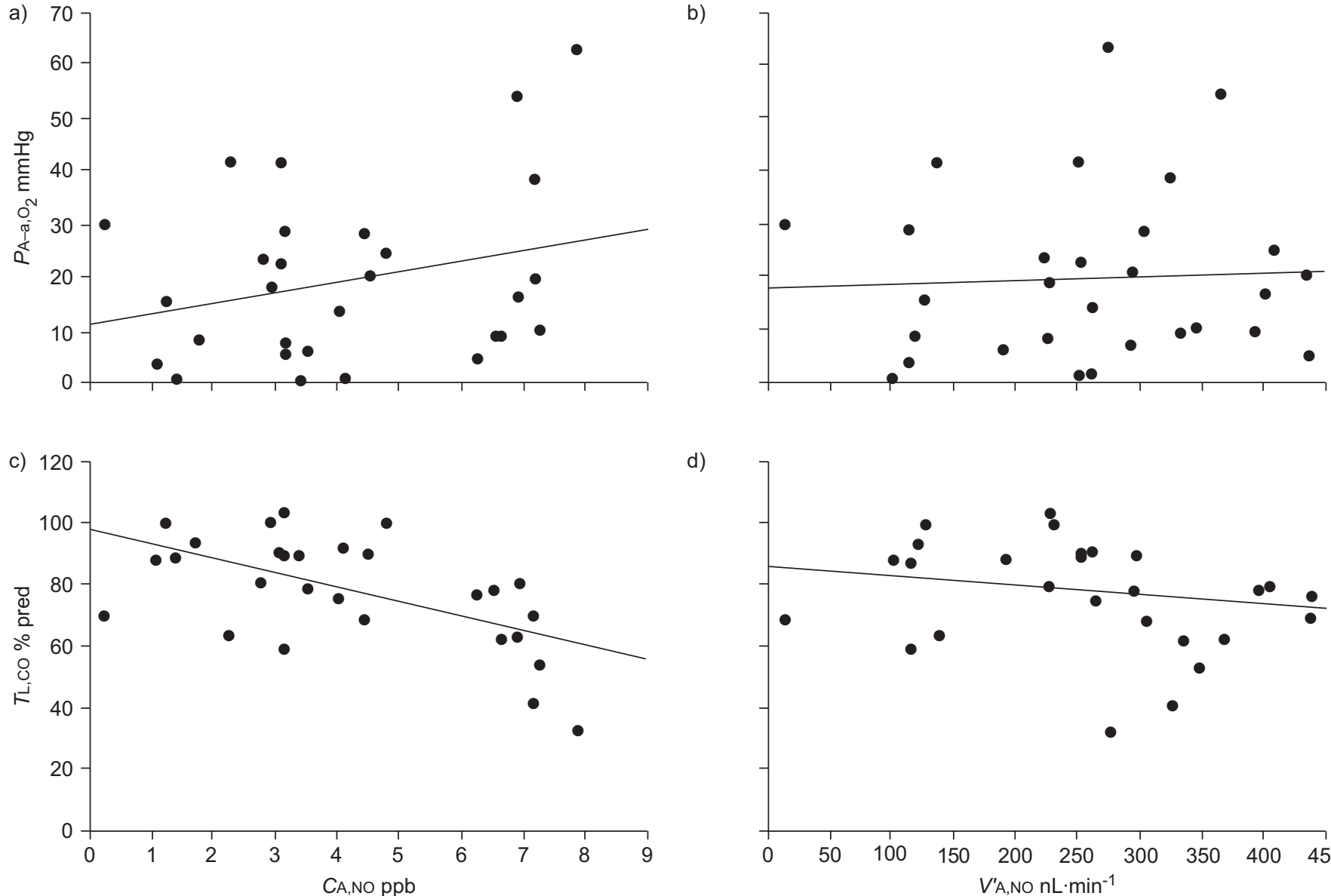

d)

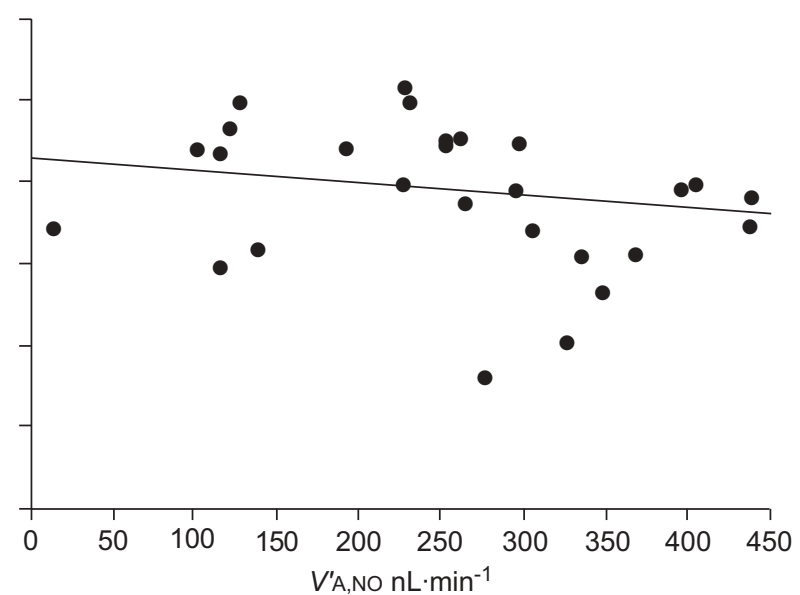

FIGURE 1. The relationship between alveolar nitric oxide concentration ( $C A, N O)$ and oxygenation parameters in 29 cirrhotic patients. a, b) There was no correlation between $C A, N O$ and alveolar-arterial oxygen tension difference $\left(P A-a, O_{2}\right)$, or between alveolar nitric oxide output $\left(V^{\prime} A, N O\right)$ and $P A-a, O_{2}$. C, d) There was a weak but significant correlation between $C A, N O$ and transfer factor of the lung for carbon monoxide $(T L, C O)$, but no correlation between $V^{\prime} A, N O$ and $\left.\left.T L, C O . a\right) r=0.18, p=0.33 . b\right) r=0.09, p=0.62$. $\left.c\right)$ $r=-0.57, p=0.001 . d) r=-0.17, p=0.33$. 


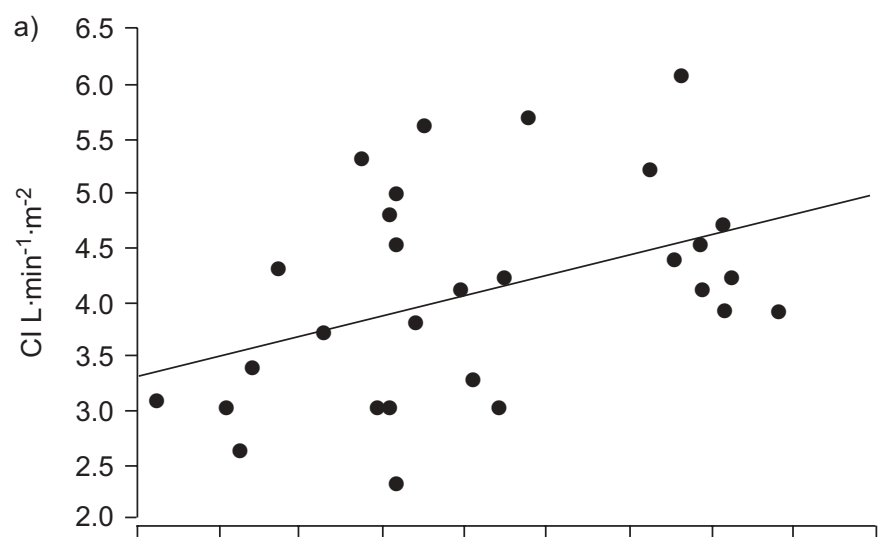

b)
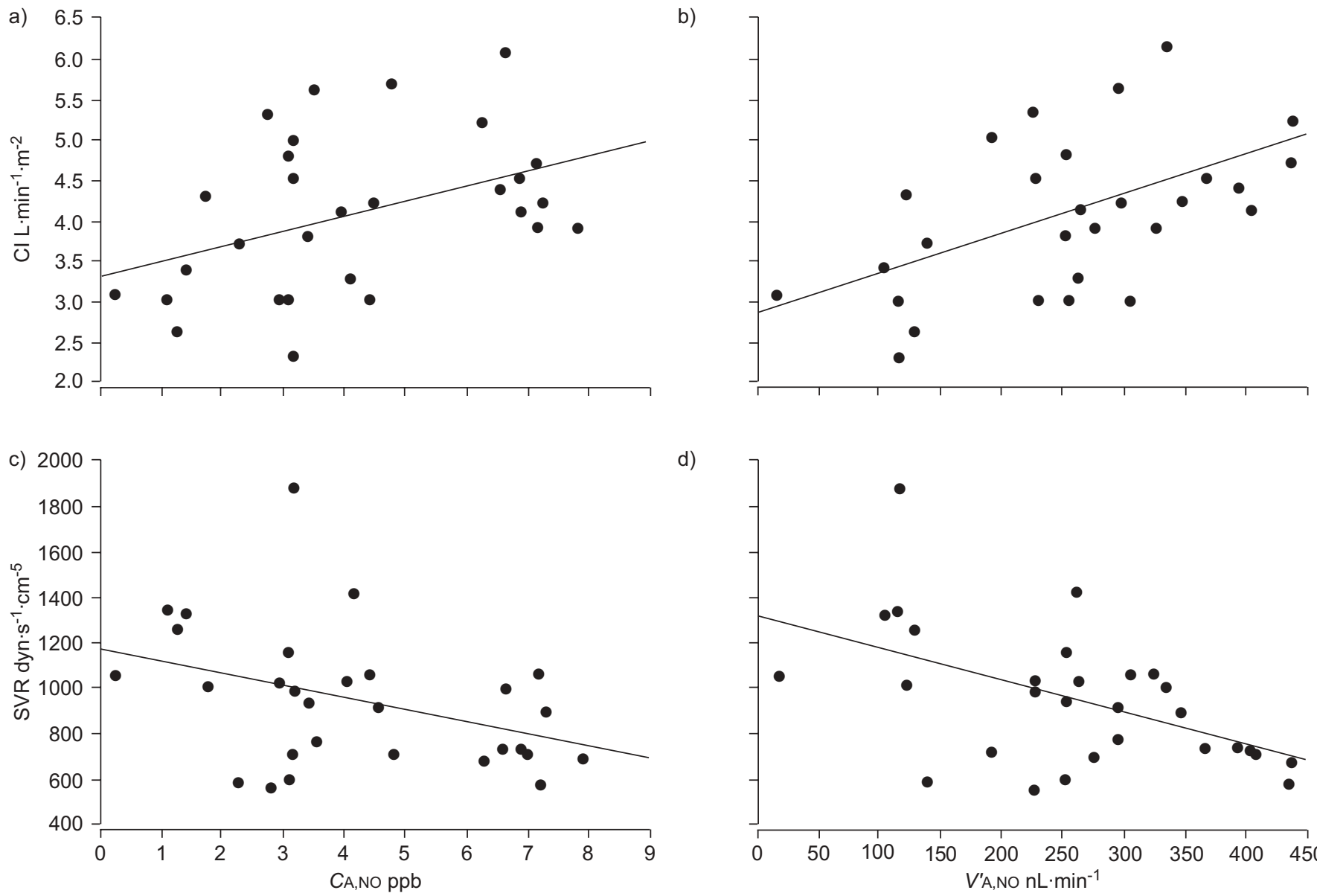

d)

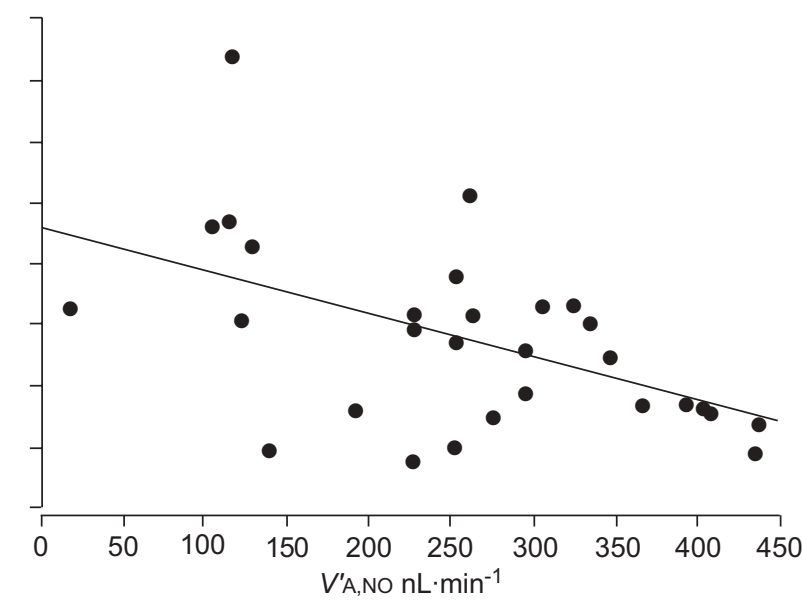

FIGURE 2. The relationship between alveolar nitric oxide concentration $(C A, N O)$ and haemodynamic parameters in 29 cirrhotic patients. a, b) Cardiac index (CI) correlated positively with $C A, N O$ and with alveolar nitric oxide output (V'A,NO). C, d) Systemic vascular resistance (SVR) correlated negatively with CA,NO and with V'A,NO. a) $r=0.41, p=0.03$. b) $r=0.56, p=0.001$. c) $r=-0.39, p=0.04$. d) $r=-0.52, p=0.004$.

estimated with this model was significantly higher than in controls, indicating that "contamination" of the alveolar compartment by NO from the airways did not account for increased values of $\mathrm{CA}, \mathrm{NO}$ in liver cirrhosis.

Increased $\mathrm{CA}, \mathrm{NO}$ may suggest either an increase of $V^{\prime} \mathrm{A}, \mathrm{NO}$ and/or a reduction of the transfer of $\mathrm{NO}$ from the alveolar compartment to the vascular compartment of the lungs $(\mathrm{TL}, \mathrm{NO})$ [14]. In patients with systemic sclerosis, GIRGIS et al. [25] concluded that the most likely cause of increased $\mathrm{CA}, \mathrm{NO}$ was decreased transfer of alveolar $\mathrm{NO}$ to the lung vessels, but TL,NO was not measured.

To the best of our knowledge, alveolar NO production has not previously been studied in cirrhotic patients. In our study, measurement of $\mathrm{TL}, \mathrm{NO}$ in addition to estimation of $\mathrm{CA}, \mathrm{NO}$ enabled us to demonstrate that the most likely cause for increased $\mathrm{CA}, \mathrm{NO}$ in cirrhotic patients was an increase of alveolar NO production. However, $\mathrm{CA}, \mathrm{NO}$ and $V^{\prime} \mathrm{A}, \mathrm{NO}$ are not strictly equivalent in these patients, as highlighted by the correlation between $\mathrm{CA}, \mathrm{NO}$ and $\mathrm{TL}, \mathrm{CO}$, which contrasts with the absence of correlation between $V^{\prime} \mathrm{A}, \mathrm{NO}$ and TL,CO.

In animal models of cirrhosis and portal hypertension, enhanced pulmonary production of NO has been clearly implicated in the development of hypoxaemia and hyperdynamic syndrome $[8,9,26,27]$. In cirrhotic patients, the relationships between pulmonary alveolar NO production, hyperdynamic circulation and gas exchange abnormalities remain uncertain. We found no correlation between alveolar $\mathrm{NO}\left(\mathrm{CA}, \mathrm{NO}\right.$ and $\left.V^{\prime} \mathrm{A}, \mathrm{NO}\right)$ and $P \mathrm{~A}-\mathrm{a}, \mathrm{O}_{2}$. In contrast, RollA et al. [24] reported a strong correlation between $P A-a, O_{2}$ and exhaled $\mathrm{NO}$ concentration, but the technique of exhaled air collection differed greatly from the methods currently recommended. DelClaUX et al. [16] found a correlation between CA,NO and PA$\mathrm{a}, \mathrm{O}_{2}$ [16]. The differences with our results may be due to: 1) differences in study population, as in the study by DELCLAUX et al. [16] patients had more severe HPS; and 2) a different mathematical model used to estimate $\mathrm{CA}, \mathrm{NO}$ [16]. Interestingly, the absence of correlation between $V^{\prime} \mathrm{A}, \mathrm{NO}$ and $\mathrm{PA}-\mathrm{a}, \mathrm{O}_{2}$ may explain, at least in part, the results of GOMEZ et al. [11], who reported that acute inhibition of pulmonary NO-synthase activity (and thus acute inhibition of pulmonary NO production) by nebulised $N^{\mathrm{G}}$-nitro-L-arginine methyl ester (L-NAME) had no effect on $\mathrm{PA}-\mathrm{a}, \mathrm{O}_{2}$. We also found that alveolar $\mathrm{NO}$ $\left(\mathrm{CA}, \mathrm{NO}\right.$ and $\left.V^{\prime} \mathrm{A}, \mathrm{NO}\right)$ correlated positively with $\mathrm{CI}$. Increased cardiac output in response to excessive vasodilatation is a hallmark of hyperdynamic circulatory syndrome [3, 6]. A possible interpretation of our finding is that NO production 
may be similarly increased in both the pulmonary and the systemic vessels in cirrhotic patients. In accordance with this interpretation, GOMEZ et al. [11] showed that nebulised LNAME decreased CI and increased both pulmonary and systemic vascular resistances in patients with hepatopulmonary syndrome.

We aimed to minimise factors confounding the measurement of FeNO. We verified that patients had neither allergy nor asthma because exhaled NO concentrations may be increased in these diseases [28]. Patients were also asked not to drink coffee on the day of measurement because caffeine has been shown to briefly reduce FeNO (for $\leqslant 4 \mathrm{~h}$ ) [29]. As nitrate-rich nutrition is presumed to increase exhaled NO concentration [30], patients were given a vegetable-free hospital diet during the $24 \mathrm{~h}$ prior to the $\mathrm{NO}$ measurements. However, 14 out of the 29 patients were regular smokers. This could be considered a bias because smoking decreases $F$ eNO, especially at relatively low expiratory flow rates (i.e. under $100 \mathrm{~mL} \cdot \mathrm{s}^{-1}$ ) [31, 32]. The smoking habits of the controls are not detailed because if exhaled NO concentrations are measured according to the current recommendations, no dose-response relationship between the number of cigarettes smoked and the levels of exhaled NO has been found in healthy subjects [20]. In accordance with previous results on the effects of tobacco smoking on exhaled $\mathrm{NO}$, we found that smokers without cirrhosis (controls) had lower NO airway production than nonsmokers. Smoking habits had no significant influence on $\mathrm{CA}, \mathrm{NO}$ and $V^{\prime} \mathrm{A}, \mathrm{NO}$ in control subjects. Moreover, our results in cirrhotic patients are in accordance with the findings of DELCLAUX et al. [16], who found no significant difference in $\mathrm{CA}, \mathrm{NO}$ or bronchial and alveolar NO outputs between smoking and nonsmoking cirrhotic patients.

We acknowledge some limitations in this study. First, we studied a small series of patients. Secondly, we included a large majority of patients without HPS or with mild-tomoderate HPS. Therefore, caution is required in extending our results to patients with severe or very severe HPS.

In summary, our results indicate that NO is produced in excess by the alveolar compartment of the lungs in advanced liver cirrhosis. In our study, alveolar NO production was associated with hyperdynamic circulatory syndrome but not with arterial oxygenation, suggesting that acute inhibition of alveolar NO production may decrease cardiac output without altering gas exchanges. Further measurements of alveolar NO output, pulmonary haemodynamics and gas exchanges following long-term NO-synthase inhibition or liver transplantation may help to understand the role of alveolar NO synthesis in advanced liver diseases.

\section{STATEMENT OF INTEREST}

None declared.

\section{REFERENCES}

1 Iwakiri Y, Groszmann RJ. Vascular endothelial dysfunction in cirrhosis. J Hepatol 2007; 46: 927-934.

2 Groszmann RJ. Hyperdynamic circulation of liver disease 40 years later: pathophysiology and clinical consequences. Hepatology 1994; 20: $1359-1363$.
3 Rodriguez-Roisin R, Krowka MJ, Herve P, et al. Pulmonaryhepatic vascular disorders (PHD). Eur Respir J 2004; 24: 861-880.

4 Herve P, Le Pavec J, Sztrymf B, et al. Pulmonary vascular abnormalities in cirrhosis. Best Pract Res Clin Gastroenterol 2007; 21: $141-159$.

5 Fallon MB, Abrams GA. Pulmonary dysfunction in chronic liver disease. Hepatology 2000; 32: 859-865.

6 Rodriguez-Roisin R, Krowka MJ. Hepatopulmonary syndrome-a liver-induced lung vascular disorder. $N$ Engl J Med 2008; 358: 2378-2387.

7 Iwakiri Y, Groszmann RJ. The hyperdynamic circulation of chronic liver diseases: from the patient to the molecule. Hepatology 2006; 43: Suppl. 1, S121-S131.

8 Nunes H, Lebrec D, Mazmanian M, et al. Role of nitric oxide in hepatopulmonary syndrome in cirrhotic rats. Am J Respir Crit Care Med 2001; 164: 879-885.

9 Sztrymf B, Rabiller A, Nunes H, et al. Prevention of hepatopulmonary syndrome and hyperdynamic state by pentoxifylline in cirrhotic rats. Eur Respir J 2004; 23: 752-758.

10 Tang L, Luo B, Patel RP, et al. Modulation of pulmonary endothelial endothelin $\mathrm{B}$ receptor expression and signaling: implications for experimental hepatopulmonary syndrome. Am J Physiol Lung Cell Mol Physiol 2007; 292: L1467-L1472.

11 Gomez FP, Barbera JA, Roca J, et al. Effects of nebulized N(G)nitro-L-arginine methyl ester in patients with hepatopulmonary syndrome. Hepatology 2006; 43: 1084-1091.

12 George SC, Hogman M, Permutt S, et al. Modeling pulmonary nitric oxide exchange. J Appl Physiol 2004; 96: 831-839.

13 Condorelli $\mathrm{P}$, Shin HW, Aledia AS, et al. A simple technique to characterize proximal and peripheral nitric oxide exchange using constant flow exhalations and an axial diffusion model. J Appl Physiol 2007; 102: 417-425.

14 Tsoukias NM, George SC. A two-compartment model of pulmonary nitric oxide exchange dynamics. J Appl Physiol 1998; 85: 653666.

15 Perillo IB, Hyde RW, Olszowka AJ, et al. Chemiluminescent measurements of nitric oxide pulmonary diffusing capacity and alveolar production in humans. J Appl Physiol 2001; 91: 1931-1940.

16 Delclaux C, Mahut B, Zerah-Lancner F, et al. Increased nitric oxide output from alveolar origin during liver cirrhosis versus bronchial source during asthma. Am J Respir Crit Care Med 2002; 165: 332-337.

17 Child CG, Turcotte JG. Surgery and portal hypertension. In: Child CG, ed. The Liver and Portal Hypertension. Saunders, Philadelphia, 1964; pp. 50-64.

18 Macintyre N, Crapo RO, Viegi G, et al. Standardisation of the single-breath determination of carbon monoxide uptake in the lung. Eur Respir J 2005; 26: 720-735.

19 Wanger J, Clausen JL, Coates A, et al. Standardisation of the measurement of lung volumes. Eur Respir J 2005; 26: 511-522.

20 Malinovschi A, Janson C, Holmkvist T, et al. Effect of smoking on exhaled nitric oxide and flow-independent nitric oxide exchange parameters. Eur Respir J 2006; 28: 339-345.

21 American Thoracic Society, European Respiratory Society, ATS/ ERS recommendations for standardized procedures for the online and offline measurement of exhaled lower respiratory nitric oxide and nasal nitric oxide, 2005. Am J Respir Crit Care Med 2005; 171: 912-930.

22 Aguilaniu B, Maitre J, Glenet S, et al. European reference equations for CO and NO lung transfer. Eur Respir J 2008; 31: 1091-1097.

23 Cremona G, Higenbottam TW, Mayoral V, et al. Elevated exhaled nitric oxide in patients with hepatopulmonary syndrome. Eur Respir J 1995; 8: 1883-1885.

24 Rolla G, Brussino L, Colagrande $P$, et al. Exhaled nitric oxide and oxygenation abnormalities in hepatic cirrhosis. Hepatology 1997; 26: 842-847. 
25 Girgis RE, Gugnani MK, Abrams J, et al. Partitioning of alveolar and conducting airway nitric oxide in scleroderma lung disease. Am J Respir Crit Care Med 2002; 165: 1587-1591.

26 Sztrymf B, Libert JM, Mougeot C, et al. Cirrhotic rats with bacterial translocation have higher incidence and severity of hepatopulmonary syndrome. J Gastroenterol Hepatol 2005; 20: 1538-1544.

27 Rabiller A, Nunes H, Lebrec D. Prevention of gram-negative translocation reduces the severity of hepatopulmonary syndrome. Am J Respir Crit Care Med 2002; 166: 514-517.

28 Bates CA, Silkoff PE. Exhaled nitric oxide in asthma: from bench to bedside. J Allergy Clin Immunol 2003; 111: 256-262.
29 Bruce C, Yates DH, Thomas PS. Caffeine decreases exhaled nitric oxide. Thorax 2002; 57: 361-363.

30 Vints AM, Oostveen E, Eeckhaut G, et al. Time-dependent effect of nitrate-rich meals on exhaled nitric oxide in healthy subjects. Chest 2005; 128: 2465-2470.

31 Hogman M, Holmkvist $\mathrm{T}$, Walinder R, et al. Increased nitric oxide elimination from the airways after smoking cessation. Clin $\mathrm{Sci}$ (Lond) 2002; 103: 15-19.

32 McSharry CP, McKay IC, Chaudhuri R, et al. Short- and long-term effects of cigarette smoking independently influence exhaled nitric oxide concentration in asthma. J Allergy Clin Immunol 2005; 116: 88-93. 